\title{
L-DOPA decarboxylase mRNA expression is associated with tumor stage and size in head and neck squamous cell carcinoma: a retrospective cohort study
}

Panagiota-Aikaterini Geomela ${ }^{1}$, Christos K Kontos ${ }^{1}$, Ioannis Yiotakis ${ }^{2}$, Emmanuel G Fragoulis ${ }^{1}$ and Andreas Scorilas ${ }^{1 *}$

\begin{abstract}
Background: Head and neck squamous cell carcinoma (HNSCC) represents one of the most commonly diagnosed malignancies worldwide. The DDC gene encodes L-DOPA decarboxylase, an enzyme catalyzing the decarboxylation of L-DOPA to dopamine. We have recently shown that DDC mRNA is a significant predictor of patients' prognosis in colorectal adenocarcinoma and prostate cancer. The aim of the current study was to analyze the DDC mRNA expression in HNSCC patients.

Methods: 53 malignant tumors were resected from the larynx, pharynx, tongue, buccal mucosa, parotid glands, and nasal cavity, as well as from 34 adjacent non-cancerous tissues of HNSCC patients, and were homogenized. Total RNA was isolated and converted into first-strand CDNA. An ultrasensitive real-time PCR method based on the SYBR Green chemistry was used for DDC mRNA quantification in head and neck tissue specimens. Relative quantification was performed using the comparative Ct $\left(2^{\text {-ddCt }}\right)$ method.

Results: DDC mRNA levels were lower in squamous cell carcinomas (SCCs) of the larynx and tongue than in adjacent non-cancerous tissue specimens. Furthermore, low DDC mRNA expression was noticed in laryngeal and tongue tumors of advanced TNM stage or bigger size, compared to early-stage or smaller tumors, respectively. No statistically significant differences were observed between SCCs resected from pharynx, buccal mucosa, or nasal cavity, and their normal counterparts.

Conclusion: This is the first study examining the DDC mRNA expression in HNSCC. According to our results, DDC mRNA expression may constitute a potential prognostic biomarker in tongue and/or larynx SCCs, which principally represent the overwhelming majority of HNSCC cases.
\end{abstract}

Keywords: Oral cancer, Larynx, Tongue, Tumor biomarkers, Quantitative real-time PCR

\section{Background}

The most usual malignancies developed in the head and neck area fall into the category of squamous cell carcinomas (SCCs) [1]. Head and neck squamous cell carcinoma (HNSCC) holds a remarkable position among the causes leading to death in the developed world [2]. In particular, this disease is endemic to Southern China and Southeast Asian countries, whereas its incidence is

\footnotetext{
* Correspondence: ascorilas@biol.uoa.gr

${ }^{1}$ Department of Biochemistry and Molecular Biology, University of Athens, Panepistimiopolis, Athens 15701, Greece

Full list of author information is available at the end of the article
}

significantly low in Europe and North America, though there is evidence of an increasing occurrence even in these areas [3]. An intermediate incidence has also been reported in Alaskan Eskimos and the Mediterranean Basin (North Africa, South Italy, Greece, and Turkey) [4]. This diversification in the HNSCC incidence among populations of distinct geographic areas implies a strong association with genetic and environmental factors [5].

HNSCC includes a great variety of tumors originating from epithelial cells lining different sites of the head and neck region. Squamous cell carcinomas arise in nasal cavity and paranasal sinuses, nasopharynx, hypolarynx, 
larynx and trachea, oral cavity, oropharynx, salivary glands, and ear, while miscellaneous tumors such as neurogenic neoplasms and paragangliomas may also appear [6]. The molecular basis of HNSCC is very complex and extremely heterogeneous, exhibiting remarkable differences even among people with tumors of the same type and stage. Research conducted during the last decade has shed light to the molecular mechanisms underlying HNSCC; yet, many essential pieces are still missing from the puzzle [2]. The discovery and prospective evaluation of novel molecular biomarkers constitute a big challenge for the scientific community [7].

The human gene encoding L-DOPA decarboxylase (DDC) maps to chromosome 7p12.1-12.3, close to the epidermal growth factor receptor $(E G F R)$ gene, and is composed of 15 exons spanning a genomic region of more than $85 \mathrm{~kb}$ [8]. Multiple alternatively spliced variants of the $D D C$ gene have been described, with most of them encoding distinct protein isoforms [9-12]. DDC is a pyridoxal-phosphate (PLP)-dependent enzyme catalyzing the decarboxylation of 3,4-dihydroxy- $L$ phenylalanine ( $L$-DOPA) to dopamine and 5-hydroxy- $L$ tryptophan (5-HTP) to serotonin [13]. DDC is localized both in the cytosol and cell membrane [14]. Enzymatically active DDC has already been detected in brain, liver, kidney, adrenal glands, pancreas, cervix [15], placenta [16], as well as in peripheral leukocytes and T-cells [17]. The presence of DDC activity in leukocytes and in the histiocytic lymphoma cell line U-937 implies a crosstalk between the nervous and the immune system, and raises new questions about the regulatory role of DDC in immune responses $[18,19]$. DDC is also a coregulator of the androgen receptor (AR) in prostate cells. In more detail, DDC exerts its function in the cytoplasm by enhancing the AR activity, and hence modulates the expression of AR-regulated genes [20,21]. Recently, the identification and purification of two novel inhibitors of the enzymatic DDC activity have been reported. One inhibitor has been isolated from the human serum and the other from the membrane fraction of human placental tissue. [22,23]. Although both inhibitors are believed to have an endogenous function, their physiological role remains to be elucidated.

Notably, DDC is regarded as a general biomarker for neuroendocrine malignancies [24-26]. For instance, elevated $D D C$ mRNA expression has been detected in small-cell lung carcinoma $[27,28]$ and neuroblastoma [29]. It has been postulated that $D D C$ mRNA expression constitutes a biomarker for the detection of minimal residual disease (MRD) in neuroblastoma patients, as well as a useful biomarker for the discrimination of neuroblastoma from other small round-cell malignancies of childhood $[29,30]$. Data from our lab support also the notion that $D D C$ mRNA expression could be used as a new tissue biomarker in prostate cancer [31], as it can reliably predict biochemical recurrence and shorter disease-free survival (DFS) interval in prostate cancer patients who have previously been subjected to radical prostatectomy [32]. In addition, Sakakura et al. showed that $D D C$ is overexpressed in peritoneal dissemination of gastric carcinoma, and suggested that $D D C$ mRNA expression is potentially a novel biomarker for the detection of peritoneal metastases [33].

Interestingly, DDC is implicated in the pathobiology of prostate cancer, since it promotes abnormal prostate cell proliferation and neuroendocrine differentiation in an AR-dependent manner [34]. Moreover, DDC seems to play a major role in cancer pathobiology and progression, since it catalyzes the synthesis of biogenic amines participating in angiogenesis, cell proliferation, and differentiation $[35,36]$. Dopamine as well as other catecholamines inhibit erythrocyte apoptosis by preventing scramblase activation and subsequent phosphatidylserine exposure on the cell membrane [37], which in turn triggers the clearance of apoptotic cells by macrophages.

The aforementioned data prompted us to analyze $D D C$ mRNA expression in HNSCC and adjacent noncancerous tissue specimens resected from patients having malignant tumors in larynx, pharynx, tongue, buccal mucosa, parotid glands, or nasal cavity, with the use of an hypersensitive quantitative real-time PCR (qRT-PCR) method based on the SYBR Green chemistry, and to evaluate its clinical significance and application as a novel tissue biomarker for HNSCC.

\section{Methods}

\section{Patients' tissue specimens}

A total of 53 malignant tumors and 34 adjacent noncancerous tissue specimens from patients having undergone surgical treatment for primary HNSCC at Athens General Hospital "Hippokration" (Athens, Greece) between 2005 and 2007, were included in the current study. Tissue specimens were resected from larynx (20 cases), pharynx (5 cases), tongue (14 cases), buccal mucosa (5 cases), parotid glands (5 cases), and nasal cavity ( 4 cases). The age of the patients included in this study varied from 34.0 to 90.0 years, with a mean \pm SE of 63.1 \pm 1.6 . All specimens incorporated in the study were selected after having taken into account the availability of sufficient tissue mass for RNA extraction and assay, while they had been frozen in liquid nitrogen immediately after their resection.

The present study was conducted in accordance with the ethical standards of the World Medical Association Declaration of Helsinki (version: 2008), and was approved by the institutional review board of Athens General Hospital "Hippokration" (Athens, Greece). Moreover, 
informed consent was obtained from HNSCC patients participating in this study.

\section{RNA extraction and reverse transcription}

Tissue specimens were pulverized and then dissolved in TRI Reagent (Ambion Europe Ltd., Huntingdon, UK). Following the manufacturer's instructions, total RNA was extracted and diluted in RNA Storage Solution (Ambion Europe Ltd.), and stored at $-80^{\circ} \mathrm{C}$ until use. First-strand cDNA was then synthesized using the MMuLV Reverse Transcriptase, RNase $\mathrm{H}^{-}$(Finnzymes Oy, Vantaa, Finland), RNaseOUT RNase inhibitor (Invitrogen, Carlsbad, CA, USA), and oligo(dT) $)_{12-18}$ as primer, according to the manufacturer's instructions.

\section{Quantitative real-time PCR (qRT-PCR)}

Taking into account the sequences of the $D D C$ and GAPDH cDNA (GenBank Accession Numbers: NM_000790 and NM_002046, respectively), we designed two pairs of gene-specific primers. The $D D C$ primers anneal to all $D D C$ transcripts except for the alt- $D D C$ variant, which possesses an alternative C-terminus [10], and give birth to a single amplicon. The sequences of the $D D C$ and GAPDH real-time PCR primers, the lengths of the PCR amplicons, and their melting temperatures $\left(\mathrm{T}_{\mathrm{m}}\right)$ are shown in Table 1. Quantitative real-time PCR (qRT-PCR) was accomplished on a 7500 Real Time PCR System (Applied Biosystems, Foster City, CA, USA) using the SYBR Green chemistry, and dissociation curves of the PCR products were next produced, as previously described [38], allowing for the discrimination of the main PCR products from primer-dimers or other non-specific products. Each real-time PCR reaction was conducted in duplicate, in order to evaluate data reproducibility.

Calculations took place with the use of the comparative $\mathrm{Ct}\left(2^{\text {-ddCt }}\right)$ method [39]. In our study, GAPDH played the role of an internal control gene for the normalization of the PCRs for the amount of RNA added to the first-strand cDNA synthesis reactions, while the colorectal adenocarcinoma epithelial cell line Caco-2 served as a calibrator. $\mathrm{ddCt}$ stands for the difference between the mean $\mathrm{dCt}$ value of a HNSCC sample and the mean $\mathrm{dCt}$ of the calibrator, both calculated after the same PCR run, while $\mathrm{dCt}$ represents the difference between the threshold cycle $(\mathrm{Ct})$ of the target gene $(D D C)$ and the $\mathrm{Ct}$ of the reference gene $(G A P D H)$ of the same sample. Normalized results were expressed as arbitrary units (a.u.), standing for the ratio of $D D C$ mRNA copies to 1000 GAPDH mRNA copies calculated for each specimen, in relation to the same ratio calculated for Caco-2 cells.

\section{Statistical analysis}

Advanced biostatistical analysis was carried out only with regard to the laryngeal squamous cell carcinoma (LSCC) and tongue squamous cell carcinoma (TSCC) specimens, since the small number of cases in the rest HNSCC patients' groups did not allow an extensive analysis to be carried out. LSCC and TSCC patients were classified in subgroups according to the TNM stage, the histological grade, and the size of their tumors; $D D C$ mRNA levels in these subgroups were compared using the non-parametric Mann-Whitney $U$ or Kruskal-Wallis test, where appropriate.

\section{Results}

Validation of the comparative $\mathrm{Ct}\left(2^{- \text {ddCt }}\right)$ method for $D D C$ mRNA quantification

The validation of the comparative $\mathrm{Ct}\left(2^{-\mathrm{ddCt}}\right)$ method, in order to be feasible, requires two presuppositions. More specifically, the PCR amplification efficiencies of the target and the reference genes should approximate to $100 \%$ and be quite equal to each other [39]. In the present study, both prerequisites were tested in a validation experiment, in which the Ct values of DDC and GAPDH cDNA amplification were determined in a dilution series of Caco- 2 cDNA over a $10^{4}$-fold range and then plotted against the $\log \mathrm{cDNA}$ dilution. The $\mathrm{Ct}$ values corresponded to the number of cycles at which the fluorescence emission monitored in real time reached a threshold of 10 times the standard deviation of the mean baseline emission from cycles 3 to 15 (Figure 1A). It should be added that all PCR products were gene-specific, as illustrated by the dissociation curves (Figure 1B). The slopes of $D D C$ and GAPDH amplification plots, as illustrated in Figure $1 C$, are similar $(-3.339$ and -3.394 , respectively). Applying the formula $E(\%)=\left[-1+10^{(-1 / \alpha)}\right] \cdot 100$, where $E(\%)$ is the real-time PCR efficiency for amplification of each gene and $\alpha$ is the slope of the corresponding amplification plot, the values of the efficiencies of $D D C$ and GAPDH PCR amplification were $99.3 \%$ and $97.1 \%$, respectively. Therefore, both prerequisites for the application of the $2^{\text {-ddCt }}$ method were satisfied.

Table 1 Primers used for real-time PCR amplification of DDC and GAPDH

\begin{tabular}{|c|c|c|c|}
\hline Gene & Primer sequence & Length of the PCR product (bp) & $\mathrm{T}_{\mathrm{m}}$ of the PCR product $\left({ }^{\circ} \mathrm{C}\right)$ \\
\hline \multirow[t]{2}{*}{$D D C$} & 5'-GAACAGACTTAACGGGAGCCTTT-3' & 90 & 79.0 \\
\hline & 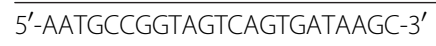 & & \\
\hline \multirow[t]{2}{*}{ GAPDH } & 5'-ATGGGGAAGGTGAAGGTCG-3' & 107 & 79.4 \\
\hline & $\overline{5^{\prime} \text {-GGGTCATTGATGGCAACAATATC-3' }}$ & & \\
\hline
\end{tabular}




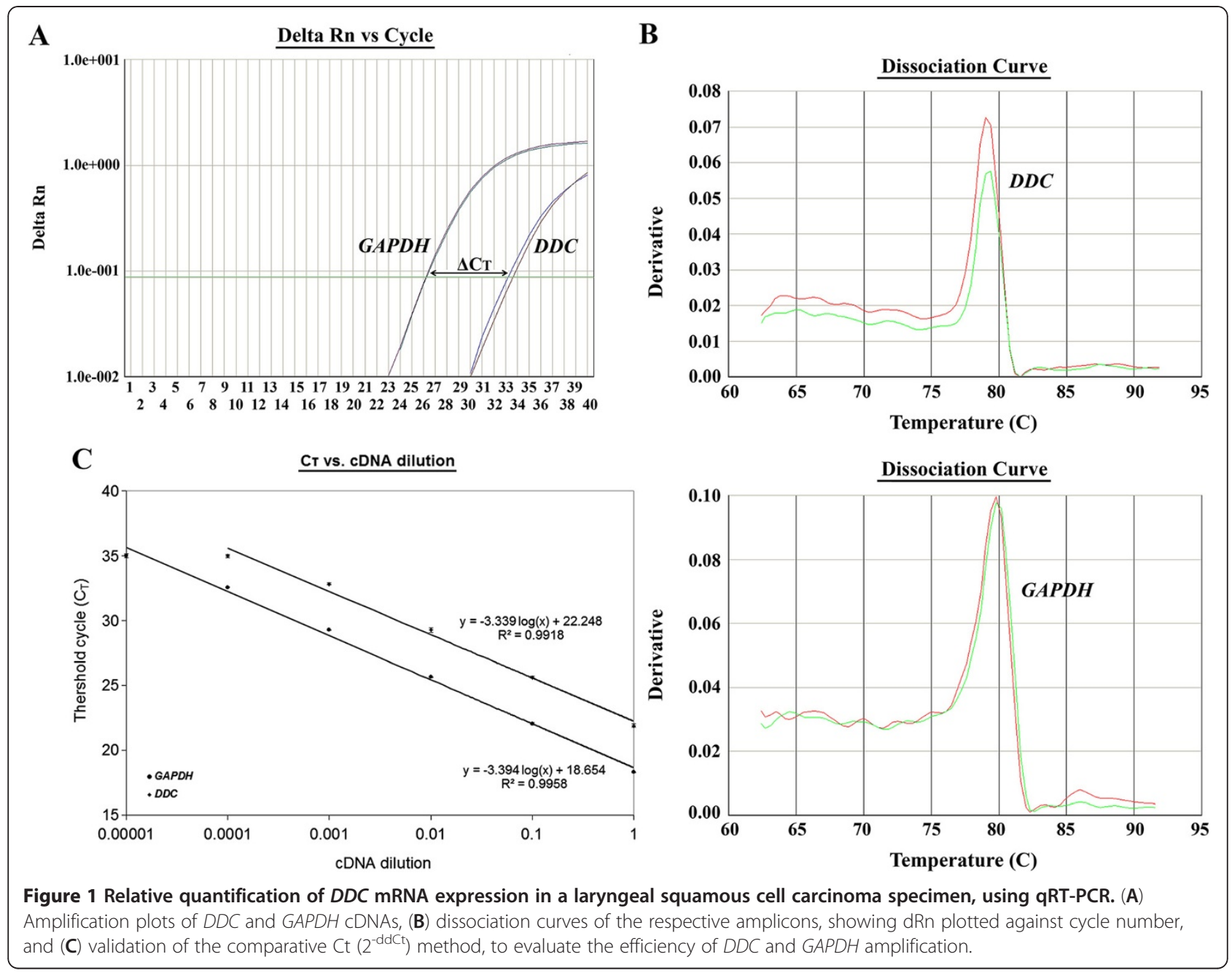

DDC mRNA expression analysis in cancerous and non-cancerous specimens of the head and neck DDC mRNA expression was lower in LSCC specimens than in non-malignant counterparts, varying between 0.05 and 164.91 a.u. with a mean \pm S.E. of $17.50 \pm 11.52$ a.u. in the former, while ranging from 0.05 to 359.72 a.u. with a mean \pm S.E. of $44.02 \pm 25.71$ a.u. in the latter (Table 2). Similarly, DDC mRNA expression levels presented a slight decrease in TSCC specimens, in comparison with their non-malignant counterparts. Therefore, DDC mRNA levels in laryngeal tumors fluctuated between 0.05 and 93.9 a.u. with a mean \pm SE of $7.43 \pm 7.21$, whereas in nonmalignant laryngeal tissue specimens they ranged from 0.05 to 128.80 a.u. with a mean \pm SE of $24.55 \pm 16.99$ (Table 2).

Table 3 shows features of the distribution of $D D C$ mRNA expression in tumors resected from pharynx, buccal mucosa, parotid glands, and nasal cavity. Because of the small number of cases of each group, only descriptive statistical analysis was performed for these results. Thus, $D D C$ mRNA levels seem to be lower in tumors of the nasal cavity than in non-cancerous counterparts. In contrast, higher levels of $D D C$ transcripts were detected in malignant neoplasms of pharynx and parotid glands, compared to their non-malignant counterparts.

\section{DDC mRNA expression analysis in subgroups of LSCC and TSCC patients}

LSCC and TSCC groups of patients were further classified in subgroups, according to classical clinicopathological parameters, such as tumor size, TNM stage, and histological grade. $D D C$ mRNA expression analysis was then conducted for each subgroup, and $D D C$ transcription levels were compared among distinct patients' subgroups using the non-parametric Mann-Whitney $U$ or KruskalWallis test, as described in the "Methods" section.

Concerning LSCC patients, those bearing small tumors exhibited remarkably increased levels of $D D C$ mRNA, in contrast to patients with bigger tumors $(\mathrm{p}=$ 0.033). In particular, in patients with tumor size $\leq 2 \mathrm{~cm}$, $D D C$ expression showed a mean \pm S.E. of $40.95 \pm 25.88$ a.u., whereas in patients with tumor size $>2 \mathrm{~cm}$ the respective 
Table 2 DDC mRNA expression ${ }^{a}$ analysis in patients with laryngeal or tongue tumors and their non-cancerous counterparts

\begin{tabular}{|c|c|c|c|c|c|c|c|}
\hline \multirow[t]{3}{*}{ Variable } & \multirow[t]{3}{*}{ Mean $\pm \mathrm{SE}^{\mathrm{b}}$} & \multirow[t]{3}{*}{ Range } & \multicolumn{5}{|c|}{ Percentiles } \\
\hline & & & 10 & 25 & 50 & 75 & 90 \\
\hline & & & & & Median & & \\
\hline$D D C$ in laryngeal tumors $(\mathrm{N}=19)$ & $17.50 \pm 11.52$ & $0.05-164.91$ & 0.05 & 0.05 & 0.05 & 0.52 & 153.89 \\
\hline$D D C$ in non-cancerous laryngeal tissues $(N=14)$ & $44.02 \pm 25.71$ & $0.05-359.72$ & 0.05 & 0.05 & 3.71 & 61.61 & 228.09 \\
\hline$D D C$ in tongue tumors $(\mathrm{N}=13)$ & $7.43 \pm 7.21$ & $0.05-93.9$ & 0.05 & 0.05 & 0.05 & 0.63 & 56.77 \\
\hline$\overline{D D C}$ in non-cancerous tongue tissues $(\mathrm{N}=8)$ & $24.55 \pm 16.99$ & $0.05-128.80$ & 0.05 & 0.05 & 0.05 & 49.92 & 128.80 \\
\hline
\end{tabular}

mean \pm S.E. was $0.42 \pm 0.37$ (Table 4). LSCC patients being at an early disease stage (TNM stage I) displayed, also, very elevated $D D C$ expression, in comparison with patients diagnosed at an intermediate (TNM stage II) or an advanced stage (TNM stage III) $(\mathrm{p}=0.027)$. On the other hand, no statistically significant difference was noticed between subgroups of TSCC patients classified according to the histological grade of the tumor.

Similarly, $D D C$ mRNA expression was found to be 2.7 -fold higher in tongue tumors of $\leq 2 \mathrm{~cm}$ than in bigger tumors $(\mathrm{p}=0.028)$. A dramatic decrease in $D D C$ gene transcription was also detected in intermediate- and late-stage TSCC patients $(\mathrm{p}=0.025)$. In more detail, in patients with TNM stage I tongue SCC, $D D C$ expression had a mean \pm S.E. of $31.73 \pm 3.11$ a.u., while in patients with tongue SCC of TNM stage II and III the mean \pm S.E. was $0.18 \pm 0.13$ and $0.05 \pm 0.003$, respectively (Table 5). No statistically significant differences were observed between subgroups of TSCC patients classified according to the tumor histological grade.

\section{Discussion}

HNSCC today represents the sixth most common malignancy affecting people in the developed countries, while the largest proportion of the cases arise in the areas of larynx and the oral cavity [1]. The leading cause of the HNSCC is predominately tobacco and alcohol abuse. Other factors which enhance the possibility of developing such tumors are the family history of the disease, which is indicative of genetic predisposition, virus infections such as HPV (human papillomavirus), EBV (Epstein-Barr virus), HSV (Herpes simplex virus) and HIV (human immunodeficiency virus), as well as an unhealthy diet and exposure to carcinogens on a permanent base, e.g. an unsanitary professional environment [3].

Undoubtedly, 5-year survival rates of advanced laryngeal and pharyngeal carcinoma patients have improved a lot during the last decade, mostly thanks to the novel therapeutic approaches that have emerged; still, the overall survival (OS) of HNSCC patients remains among the lowest. Usually, treatment strategies fail or procure rather modest improvement and consequently, locoregional recurrence, distant metastases, and second primary tumors are frequent. In particular, positive nodal status is considered as the most adverse independent prognosticator in HNSCC [7]. Despite the recent advances, the morbidity and the mortality attributed to this disease remain among the highest [2]. The poor prognosis of HNSCC patients is mostly due to lack of established biomarkers for early detection and treatment monitoring [40]. Taking all this information into consideration, the discovery of novel, reliable molecular biomarkers for HNSCC may contribute to the prolongation of patients' survival through early diagnosis, reliable prognosis and/or effective treatment response monitoring, while it may also illuminate the molecular background of this cancer type [41].

Table 3 Distribution of DDC mRNA expression ${ }^{\mathrm{a}}$ in head and neck squamous cell carcinomas and in non-cancerous counterparts

\begin{tabular}{|c|c|c|c|c|c|c|}
\hline \multirow[t]{2}{*}{ Tissue } & \multicolumn{3}{|c|}{ Cancerous samples } & \multicolumn{3}{|c|}{ Non-cancerous samples } \\
\hline & Mean $\pm \mathrm{SE}^{\mathrm{b}}$ & Median & Range & Mean $\pm S E^{b}$ & Median & Range \\
\hline Pharynx & $5.51 \pm 4.66$ & 0.20 & $0.05-23.98$ & $4.21 \pm 3.5$ & 1.07 & $0.05-14.65$ \\
\hline Buccal mucosa & $2.71 \pm 2.66$ & 0.05 & $0.05-13.33$ & - & - & - \\
\hline Parotid glands & $2.23 \pm 1.88$ & 0.10 & $0.05-9.69$ & $0.31 \pm 0.26$ & 0.05 & $0.05-1.07$ \\
\hline Nasal cavity & $0.39 \pm 0.24$ & 0.23 & $0.05-1.05$ & $8.75 \pm 8.69$ & 0.05 & $0.05-26.13$ \\
\hline
\end{tabular}

a a.u.: arbitrary units.

b Standard error of the mean. 
Table 4 DDC mRNA expression ${ }^{\text {a }}$ analysis in subgroups of LSCC patients, classified according to classical clinicopathological parameters

\begin{tabular}{lcccc}
\hline Variable & No. of patients & Mean $\pm \mathbf{S E}^{\mathbf{b}}$ & Median & p value \\
\hline Tumor size & & & \\
\hline$\leq 2 \mathrm{~cm}$ & 8 & $40.95 \pm 25.88$ & 0.41 & $0.033^{\mathrm{c}}$ \\
\hline$>2 \mathrm{~cm}$ & 11 & $0.42 \pm 0.37$ & 0.05 & \\
\hline TNM stage & & & & \\
\hline I & 5 & $63.94 \pm 39.01$ & 0.52 & $0.027^{\mathrm{d}}$ \\
\hline II & 3 & $2.65 \pm 2.61$ & 0.05 & \\
\hline III & 11 & $0.42 \pm 0.37$ & 0.05 & \\
\hline Histological grade & & & & \\
\hline I & 7 & $0.12 \pm 0.07$ & 0.05 & $0.46^{\mathrm{d}}$ \\
\hline II & 6 & $28.22 \pm 27.35$ & 0.05 & \\
\hline III & 6 & $27.03 \pm 25.40$ & 0.17 & \\
\hline
\end{tabular}

a a.u.: arbitrary units.

b Standard error of the mean.

c Calculated using the Mann-Whitney $U$ test.

${ }^{d}$ Calculated using the Kruskal-Wallis test.

To date, several molecules have been evaluated and proposed as potential biomarkers in HNSCC, including $E G F R$, cyclin D1 (CCND1), Ki67 antigen, FAS, FASL, $B C L 2$, BCL2L12, TP53, P27, vascular endothelial growth factor (VEGF), matrix metallopeptidases (MMPs), and kallikrein-related peptidases (KLKs) [7,42-46]. Our study introduces the mRNA expression of $D D C$ as a new promising tumor biomarker for HNSCC. DDC mRNA expression has already been demonstrated to increase in many tissues; modulations in its expression levels have been reported in various malignancies, such as neuroblastoma [30], small cell lung carcinoma [16], and

Table 5 DDC mRNA expression ${ }^{a}$ analysis in subgroups of TSCC patients, classified according to classical clinicopathological parameters

\begin{tabular}{lcccc}
\hline Variable & No. of patients & Mean $\pm \mathbf{S E}^{\mathbf{b}}$ & Median & p value \\
\hline Tumor size & & & \\
\hline$\leq 2 \mathrm{~cm}$ & 7 & $13.76 \pm 3.36$ & 0.26 & $0.028^{\mathrm{c}}$ \\
\hline$>2 \mathrm{~cm}$ & 6 & $5.08 \pm 0.02$ & 0.05 & \\
\hline TNM stage & & & \\
\hline I & 3 & $31.73 \pm 3.11$ & 1.00 & $0.025^{d}$ \\
\hline II & 7 & $0.18 \pm 0.13$ & 0.05 & \\
\hline III & 3 & $0.05 \pm 0.003$ & 0.05 & \\
\hline Histological grade & & & & \\
\hline I & 5 & $0.24 \pm 0.19$ & 0.05 & $0.097^{d}$ \\
\hline II & 4 & $0.28 \pm 0.23$ & 0.05 & \\
\hline III & 3 & $31.34 \pm 31.29$ & 0.05 & \\
\hline
\end{tabular}

a a.u.: arbitrary units.

b Standard error of the mean.

c Calculated using the Mann-Whitney $U$ test.

${ }^{d}$ Calculated using the Kruskal-Wallis test. prostate cancer [20,31]. Most interestingly, strong DDC mRNA expression has been detected in tumors of the gastrointestinal tract [33,38].

Extremely high DDC activity in neoplastic cells is a hallmark of several peripheral cancers. This is mostly apparent in lung tumors of small-cell origin, although nonsense alternatively spliced variants are also present [35]. Furthermore, a remarkable increase in DDC activity has been detected in primary intestinal cancer as well as in its related metastases in the spleen and liver, in comparison with normal tissue [25]. The significance of elevated DDC activity and increased monoamine synthesis by the neoplastic cells remains to be elucidated [35]; still, it is closely related to the involvement of DDC in cancer.

In this study, we undertook the quantitative expression analysis of DDC mRNA in SCCs of the larynx, pharynx, tongue, buccal mucosa, parotid glands, and nasal cavity, as well as in adjacent non-cancerous counterparts. Our results revealed that DDC mRNA levels are 2.5- and 3.3fold lower in laryngeal and tongue tumors, respectively, than in non-cancerous adjacent tissues. Moreover, $D D C$ mRNA expression differs significantly in LSCC and TSCC patients, when classified according to the TNM stage or size of malignant tumors. Concretely, LSCC patients bearing tumors of early TNM stage and/or smaller than $2 \mathrm{~cm}$ displayed higher $D D C$ mRNA expression than patients with more advanced tumors. The decreased $D D C$ mRNA expression that seems to be associated with progression of HNSCC could imply a protective role of DDC against HNSCC, perhaps owing to its indirect association with apoptosis [37]. In spite of the fact that clinical comorbidities have been shown to significantly affect survival over TNM prognosticators [47], the TNM classification consistently correlates with DFS and OS [48]. Given that the TNM staging of LSCC remains the most significant predictor of survival and that $D D C$ mRNA levels are high in early-stage patients, $D D C$ could constitute a favorable prognostic indicator in LSCC. Moreover, $D D C$ has a similar expression pattern in colorectal adenocarcinoma, possessing favorable prognostic value. Elevated $D D C$ mRNA expression levels were found in well-differentiated and early-stage colorectal adenocarcinomas, and were shown to predict better patient outcome, in terms of DFS and OS [38]. The prognostic potential of $D D C$ mRNA status in prostate cancer has also recently been uncovered. In more detail, $D D C$ mRNA is likely to constitute an unfavorable prognosticator in this malignancy, predicting biochemical recurrence and poor DFS in prostate cancer patients treated by radical prostatectomy [32]. Additionally, $D D C$ mRNA levels were shown to be significantly higher in prostate cancer than in benign prostate hyperplasia patients. Therefore, $D D C$ mRNA status seems to possess significant discriminatory value in this malignancy [31]. 
On the other hand, increased $D D C$ expression is associated with peritoneal metastasis, since its mRNA is upregulated in gastric cancer peritoneal dissemination [33]. This discrepancy could be attributed to the utilization of distinct gene promoters [49], which regulate the expression of this gene in a tissue-specific manner [50]. In fact, several molecules have been shown to be overexpressed in various malignancies, while being downregulated in other types of cancer. For instance, $B C L 2 L 12$, a member of the BCL2 family of apoptosisrelated genes, is overexpressed in undifferentiated nasopharyngeal carcinoma [43] and in poorly differentiated TSCC, whereas its mRNA levels are lower in LSCC of advanced TNM stage, compared to early-stage laryngeal tumors [45].

In this framework, the potential correlation between $D D C$ mRNA expression and DFS and/or OS of LSCC patients deserves further investigation. Hence, our future goals include $D D C$ mRNA expression analysis in larger cohorts of LSCC and TSCC samples in order to validate the current results, since the number of SCC specimens used in this study constitutes a limiting factor, owing to the fact that HNSCC is not a very common cancer type in Greece [51]. Furthermore, the statistically significant correlation of $D D C$ expression with the tumor size and the TNM stage of the disease, as confirmed in LSCC and TSCC patients, might contribute to more accurate and effective staging of laryngeal and tongue tumors, respectively. The implementation of molecular criteria in disease staging may aid to distinguish between neoplasms which, though different at the molecular level, are grouped together, based on the current morphological and clinicopathological parameters. To sum up, this study proposes $D D C$ mRNA expression as a useful biomarker for better classification of the laryngeal and tongue tumors. Although mRNA levels are heavily dependent on ribonuclease activity, $D D C$ mRNA expression, if combined with other putative biomarkers, could add to their prognostic value or be part of a multiparametric model significantly assisting with HNSCC classification, prognosis, and response to chemotherapy.

\section{Conclusion}

To the best of our knowledge, this is the first time that this gene is studied in HNSCC. Our results imply the clinical usefulness of $D D C$ mRNA expression as a potential prognostic biomarker in TSCC and/or LSCC, which principally compose the vast majority of HNSCC cases. Additional studies could shed light to the molecular mechanisms underlying the role of DDC in HNSCC progression, and thoroughly examine the prognostic value of DDC mRNA expression in LSCC, TSCC, and other types of HNSCC. With regard to our future goals, we are planning to compare the $D D C$ mRNA expression profile in a larger cohort of LSCC and TSCC patients, and in healthy controls. The expression analysis will also discriminate between distinct variants of the $D D C$ gene. Furthermore, we intend to assess the prognostic value of this potential biomarker in HNSCC and to examine the effect of widely used chemotherapy on $D D C$ expression.

\section{Abbreviations}

SCC: Squamous cell carcinoma; HNSCC: Head and neck squamous cell carcinoma; DDC: L-DOPA decarboxylase; EGFR: Epidermal growth factor receptor; PLP: Pyridoxal-phosphate; L-DOPA: 3:4-dihydroxy-L-phenylalanine; 5-HTP: 5-hydroxy-L-tryptophan; AR: Androgen receptor; MRD: Minimal residual disease; qRT-PCR: Quantitative real-time PCR; cDNA: DNA complementary to RNA; RNase: Ribonuclease; Oligo(dT): Oligodeoxythymidine; GAPDH: Glyceraldehyde-3-phosphate dehydrogenase; a.u: Arbitrary units; LSCC: Laryngeal squamous cell carcinoma; TSCC: Tongue squamous cell carcinoma; HPV: Human papillomavirus; EBV: Epstein-Barr virus; HSV: Herpes simplex virus; HIV: Human immunodeficiency virus; OS: Overall survival; DFS: Disease-free survival.

\section{Competing interests}

The authors declare that they have no competing interests.

\section{Authors' contributions}

PAG carried out the experimental work, collected and analyzed data, and drafted the manuscript. CKK interpreted the results and drafted the manuscript. IY designed the study, collected patients' material and follow-up data. EGF revised critically the manuscript. AS conceived of the study, coordinated the study, and performed the statistical analysis. All authors read and approved the final manuscript

\section{Acknowledgements}

This work was financially supported by the Commission of the European Community through the INsPiRE project (EU-FP7-REGPOT-2011-1, proposal 284460).

\section{Author details}

${ }^{1}$ Department of Biochemistry and Molecular Biology, University of Athens, Panepistimiopolis, Athens 15701, Greece. ${ }^{2}$ First Ear, Nose \& Throat Clinics, Athens General Hospital 'Hippokration, University of Athens, 114 Vasilissis Sofias Ave, Athens 11527, Greece.

Received: 19 June 2012 Accepted: 17 October 2012

Published: 20 October 2012

\section{References}

1. Chin D, Boyle GM, Porceddu S, Theile DR, Parsons PG, Coman WB: Head and neck cancer: past, present and future. Expert Rev Anticancer Ther 2006, 6:1111-1118.

2. Perez-Ordonez B, Beauchemin M, Jordan RC: Molecular biology of squamous cell carcinoma of the head and neck. J Clin Pathol 2006, 59:445-453.

3. Argiris A, Karamouzis MV, Raben D, Ferris RL: Head and neck cancer. Lancet 2008, 371:1695-1709.

4. Chan AT, Teo PM, Johnson PJ: Nasopharyngeal carcinoma. Ann Oncol 2002, 13:1007-1015

5. Busson P, Keryer C, Ooka T, Corbex M: EBV-associated nasopharyngeal carcinomas: from epidemiology to virus-targeting strategies. Trends Microbiol 2004, 12:356-360.

6. Patel SG, Shah JP: TNM staging of cancers of the head and neck: striving for uniformity among diversity. CA Cancer J Clin 2005, 55:242-258. quiz 261-242, 264.

7. Lothaire P, de Azambuja E, Dequanter D, Lalami Y, Sotiriou C, Andry G, Castro G Jr, Awada A: Molecular markers of head and neck squamous cell carcinoma: promising signs in need of prospective evaluation. Head Neck 2006, 28:256-269.

8. Ichinose H, Kurosawa Y, Titani K, Fujita K, Nagatsu T: Isolation and characterization of a CDNA clone encoding human aromatic L-amino acid decarboxylase. Biochem Biophys Res Commun 1989, 164:1024-1030. 
9. O'Malley KL, Harmon S, Moffat M, Uhland-Smith A, Wong S: The human aromatic L-amino acid decarboxylase gene can be alternatively spliced to generate unique protein isoforms. J Neurochem 1995, 65:2409-2416.

10. Vassilacopoulou D, Sideris DC, Vassiliou AG, Fragoulis EG: Identification and characterization of a novel form of the human L-dopa decarboxylase mRNA. Neurochem Res 2004, 29:1817-1823.

11. Ichinose H, Sumi-Ichinose C, Ohye T, Hagino Y, Fujita K, Nagatsu T: Tissue-specific alternative splicing of the first exon generates two types of mRNAs in human aromatic L-amino acid decarboxylase. Biochemistry 1992, 31:11546-11550.

12. Krieger M, Coge F, Gros F, Thibault J: Different mRNAs code for dopa decarboxylase in tissues of neuronal and nonneuronal origin. Proc Natl Acad Sci USA 1991, 88:2161-2165.

13. Christenson JG, Dairman W, Udenfriend S: On the identity of DOPA decarboxylase and 5-hydroxytryptophan decarboxylase (immunological titration-aromatic L-amino acid decarboxylase-serotonin-dopaminenorepinephrine). Proc Natl Acad Sci USA 1972, 69:343-347.

14. Chalatsa I, Fragoulis EG, Vassilacopoulou D: Release of membraneassociated L-dopa decarboxylase from human cells. Neurochem Res 2011, 36:1426-1434.

15. Florou D, Scorilas A, Vassilacopoulou D, Fragoulis EG: DDC (dopa decarboxylase (aromatic L-amino acid decarboxylase)). Atlas Genet Cytogenet Oncol Haematol 2011, 15:949-957.

16. Siaterli MZ, Vassilacopoulou D, Fragoulis EG: Cloning and expression of human placental L-Dopa decarboxylase. Neurochem Res 2003, 28:797-803.

17. Kokkinou I, Nikolouzou E, Hatzimanolis A, Fragoulis EG, Vassilacopoulou D: Expression of enzymatically active L-DOPA decarboxylase in human peripheral leukocytes. Blood Cells Mol Dis 2009, 42:92-98.

18. Kokkinou I, Fragoulis EG, Vassilacopoulou D: The U937 macrophage cell line expresses enzymatically active L-Dopa decarboxylase. J Neuroimmunol 2009, 216:51-58.

19. Kerr JF, Wyllie AH, Currie AR: Apoptosis: a basic biological phenomenon with wide-ranging implications in tissue kinetics. Br J Cancer 1972, 26:239-257.

20. Margiotti K, Wafa LA, Cheng H, Novelli G, Nelson CC, Rennie PS: Androgenregulated genes differentially modulated by the androgen receptor coactivator L-dopa decarboxylase in human prostate cancer cells. $\mathrm{Mol}$ Cancer 2007, 6:38.

21. Wafa LA, Cheng H, Rao MA, Nelson CC, Cox M, Hirst M, Sadowski I, Rennie PS: Isolation and identification of L-dopa decarboxylase as a protein that binds to and enhances transcriptional activity of the androgen receptor using the repressed transactivator yeast two-hybrid system. Biochem $\mathrm{J}$ 2003, 375:373-383

22. Vassiliou AG, Fragoulis EG, Vassilacopoulou D: Detection, purification and identification of an endogenous inhibitor of L-Dopa decarboxylase activity from human placenta. Neurochem Res 2009, 34:1089-1100.

23. Vassiliou AG, Vassilacopoulou D, Fragoulis EG: Purification of an endogenous inhibitor of L-Dopa decarboxylase activity from human serum. Neurochem Res 2005, 30:641-649.

24. Gazdar AF, Helman LJ, Israel MA, Russell EK, Linnoila Rl, Mulshine JL, Schuller HM, Park JG: Expression of neuroendocrine cell markers L-dopa decarboxylase, chromogranin A, and dense core granules in human tumors of endocrine and nonendocrine origin. Cancer Res 1988, 48:4078-4082

25. Gilbert JA, Bates LA, Ames MM: Elevated aromatic-L-amino acid decarboxylase in human carcinoid tumors. Biochem Pharmacol 1995, 50:845-850

26. Ippolito JE, Xu J, Jain S, Moulder K, Mennerick S, Crowley JR, Townsend RR, Gordon Jl: An integrated functional genomics and metabolomics approach for defining poor prognosis in human neuroendocrine cancers. Proc Natl Acad Sci USA 2005, 102:9901-9906.

27. Gilbert JA, Frederick LM, Ames MM: The aromatic-L-amino acid decarboxylase inhibitor carbidopa is selectively cytotoxic to human pulmonary carcinoid and small cell lung carcinoma cells. Clin Cancer Res 2000, 6:4365-4372.

28. Jensen SM, Gazdar AF, Cuttitta F, Russell EK, Linnoila Rl: A comparison of synaptophysin, chromogranin, and L-dopa decarboxylase as markers for neuroendocrine differentiation in lung cancer cell lines. Cancer Res 1990, 50:6068-6074

29. Gilbert J, Haber M, Bordow SB, Marshall GM, Norris MD: Use of tumorspecific gene expression for the differential diagnosis of neuroblastoma from other pediatric small round-cell malignancies. Am J Pathol 1999, 155:17-21.

30. Bozzi F, Luksch R, Collini P, Gambirasio F, Barzano E, Polastri D, Podda M, Brando B, Fossati-Bellani F: Molecular detection of dopamine decarboxylase expression by means of reverse transcriptase and polymerase chain reaction in bone marrow and peripheral blood: utility as a tumor marker for neuroblastoma. Diagn Mol Pathol 2004, 13:135-143.

31. Avgeris M, Koutalellis G, Fragoulis EG, Scorilas A: Expression analysis and clinical utility of L-Dopa decarboxylase (DDC) in prostate cancer. Clin Biochem 2008, 41:1140-1149.

32. Koutalellis G, Stravodimos K, Avgeris M, Mavridis K, Scorilas A, Lazaris A, Constantinides C: L-dopa decarboxylase (DDC) gene expression is related to outcome in patients with prostate cancer. BJU Int 2012, 110:E267-E273.

33. Sakakura C, Takemura M, Hagiwara A, Shimomura K, Miyagawa K, Nakashima S, Yoshikawa T, Takagi T, Kin S, Nakase Y, et al: Overexpression of dopa decarboxylase in peritoneal dissemination of gastric cancer and its potential as a novel marker for the detection of peritoneal micrometastases with real-time RT-PCR. Br J Cancer 2004, 90:665-671.

34. Wafa LA, Palmer J, Fazli L, Hurtado-Coll A, Bell RH, Nelson CC, Gleave ME, Cox ME, Rennie PS: Comprehensive expression analysis of L-dopa decarboxylase and established neuroendocrine markers in neoadjuvant hormone-treated versus varying Gleason grade prostate tumors. Hum Pathol 2007, 38:161-170.

35. Berry MD, Juorio AV, Li XM, Boulton AA: Aromatic L-amino acid decarboxylase: a neglected and misunderstood enzyme. Neurochem Res 1996, 21:1075-1087.

36. Medina MA, Quesada AR, Nunez de Castro I, Sanchez-Jimenez F: Histamine, polyamines, and cancer. Biochem Pharmacol 1999, 57:1341-1344.

37. Lang PA, Kempe DS, Akel A, Klarl BA, Eisele K, Podolski M, Hermle T, Niemoeller OM, Attanasio P, Huber SM, et al: Inhibition of erythrocyte "apoptosis" by catecholamines. Naunyn Schmiedebergs Arch Pharmacol 2005, 372:228-235.

38. Kontos CK, Papadopoulos IN, Fragoulis EG, Scorilas A: Quantitative expression analysis and prognostic significance of L-DOPA decarboxylase in colorectal adenocarcinoma. Br J Cancer 2010, 102:1384-1390.

39. Schmittgen TD, Livak KJ: Analyzing real-time PCR data by the comparative C(T) method. Nat Protoc 2008, 3:1101-1108.

40. Rodrigo JP, Ferlito A, Suarez C, Shaha AR, Silver CE, Devaney KO, Bradley PJ, Bocker JM, McLaren KM, Grenman R, Rinaldo A: New molecular diagnostic methods in head and neck cancer. Head Neck 2005, 27:995-1003.

41. Sotiriou C, Lothaire P, Dequanter D, Cardoso F, Awada A: Molecular profiling of head and neck tumors. Curr Opin Oncol 2004, 16:211-214.

42. Fendri A, Kontos CK, Khabir A, Mokdad-Gargouri R, Ardavanis A, Scorilas A: Quantitative analysis of BCL2 mRNA expression in nasopharyngeal carcinoma: an unfavorable and independent prognostic factor. Tumour Biol 2010, 31:391-399.

43. Fendri A, Kontos CK, Khabir A, Mokdad-Gargouri R, Scorilas A: BCL2L12 is a novel biomarker for the prediction of short-term relapse in nasopharyngeal carcinoma. Mol Med 2011, 17:163-171.

44. Kontos CK, Scorilas A: Kallikrein-related peptidases (KLKs): a gene family of novel cancer biomarkers. Clin Chem Lab Med CCLM / FESCC 2012, doi: 10.1515/cclm-2012-0247.

45. Geomela PA, Kontos CK, Yiotakis I, Scorilas A: Quantitative expression analysis of the apoptosis-related gene, BCL2L12, in head and neck squamous cell carcinoma. J Oral Pathol Med 2012, doi: 10.1111/j.16000714.2012.01190.x

46. Patsis C, Yiotakis I, Scorilas A: Diagnostic and prognostic significance of human kallikrein 11 (KLK11) mRNA expression levels in patients with laryngeal cancer. Clin Biochem 2012, 45:623-630.

47. Piccirillo JF, Lacy PD, Basu A, Spitznagel EL: Development of a new head and neck cancer-specific comorbidity index. Arch Otolaryngol Head Neck Surg 2002, 128:1172-1179.

48. Nguyen-Tan PF, Le QT, Quivey JM, Singer M, Terris DJ, Goffinet DR, Fu KK: Treatment results and prognostic factors of advanced T3-4 laryngeal carcinoma: the University of California, San Francisco (UCSF) and Stanford University Hospital (SUH) experience. Int J Radiat Oncol Biol Phys 2001, 50:1172-1180.

49. Chireux M, Raynal JF, Le Van Thai A, Cadas H, Bernard C, Martinou I, Martinou JC, Weber MJ: Multiple promoters of human choline acetyltransferase and aromatic L-amino acid decarboxylase genes. J Physiol Paris 1994, 88:215-227. 
50. Sumi-Ichinose C, Hasegawa S, Ichinose H, Sawada H, Kobayashi K, Sakai M, Fujii T, Nomura H, Nomura T, Nagatsu I, et al: Analysis of the alternative promoters that regulate tissue-specific expression of human aromatic L-amino acid decarboxylase. J Neurochem 1995, 64:514-524.

51. Patsis C, Glyka V, Yiotakis I, Fragoulis EG, Scorilas A: L-DOPA decarboxylase (DDC) expression status as a novel molecular tumor marker for diagnostic and prognostic purposes in laryngeal cancer. Transl Oncol 2012, 5:288-296

doi:10.1186/1471-2407-12-484

Cite this article as: Geomela et al:: L-DOPA decarboxylase mRNA expression is associated with tumor stage and size in head and neck squamous cell carcinoma: a retrospective cohort study. BMC Cancer 2012 12:484.

\section{Submit your next manuscript to BioMed Central and take full advantage of:}

- Convenient online submission

- Thorough peer review

- No space constraints or color figure charges

- Immediate publication on acceptance

- Inclusion in PubMed, CAS, Scopus and Google Scholar

- Research which is freely available for redistribution 